\title{
ENTRE EMOÇÃO E COGNIÇÃO: UMA ETNOGRAFIA COMO PROJETO REFLEXIVO ${ }^{1}$
}

\author{
Astrid Johana Pardo Gonzalez ${ }^{2}$
}

RESUMO: No seguinte texto realizaremos uma discussão metodológica sobre a etnografia denominada reflexiva, na qual a pesquisadora explicita uma forma de fazer a observação, onde se vinculam e se misturam aspectos cognitivos e emotivos. Desta forma, faremos um percurso pela construção do objeto de pesquisa, que como veremos, está relacionado à formação acadêmica da pesquisadora, assim como à forma como se produziu sua aproximação ao campo. Esta análise faz parte de uma dissertação de mestrado do PPCIS/UERJ, pesquisa que teve como objetivo analisar as gramáticas emocionais no grupo de ajuda mútua Mulheres que Amam demais Anônimas, MADA.

Recebido em: Setembro 2014 Aceito em: Dezembro 2014

Para citar este artigo:

GONZALEZ, Astrid; "Entre emoção e cognição: uma etnografia como projeto reflexivo." In: Revista Intratextos, 2014, vol 5, no 1, p. 95-115. DOI: http://dx.doi.org/10.12957/intratextos.2014.12905

10 seguinte artigo faz parte de uma dissertação do mestrado do PPCIS/ UERJ, pesquisa que teve como objetivo analisar as gramáticas emocionais no grupo de ajuda mutua Mulheres que Amam demais Anônimas MADA- inspirado no livro da autora estadunidense Robin Norwood que leva o mesmo nome -, teve início no Brasil na cidade de São Paulo em 1994. Atualmente realizam-se mais de 45 reuniões semanais distribuídas em 14 Estados e no Distrito Federal. Sabe-se da existência do grupo na Espanha, em Portugal e na Venezuela. O grupo baseia sua recuperação no programa dos doze passos dos alcoólicos anônimos, que foi adaptado ao MADA. Compara-se com outros grupos de dependentes, sendo sua "droga" o amor excessivo, o qual define como uma doença. 2 Doutoranda em Ciências Sociais pelo PPCIS/UERJ. Bolsista Faperj.mail:johanitapardog@ gmail.com 
A palavra subjetividade, tanto no espanhol quanto no português, duas línguas com as quais convivo cotidianamente, tem dois significados: por um lado, o relativo aos sujeitos e por outro, como antônimo de objetividade. Estas duas acepções têm relação direta com minha pesquisa a nível epistemológico e metodológico, dado que como projeto de vida acadêmica me propus estudar os processos de construção de sujeitos através de um enfoque etnográfico que pressupõe a não existência da objetividade, mas sim um envolvimento da pesquisadora no campo de um modo que denominarei reflexivo.

A questão da não objetividade na antropologia faz parte de um debate que começa a surgir desde os anos setenta, que de alguma forma está relacionado com o impacto da publicação do diário de Malinowski onde o mito do pesquisador "semicamaleônico" e "científico", totalmente objetivo e empático com seus informantes, foi derrubado .Segundo Geertz isto foi apenas a dramatização de uma série de problemas metodológicos que se apresentavam de diferentes formas:

...descrições que são vistas "de dentro" versus as que são vistas "de fora", ou
descrições "na primeira pessoa" versus aquelas "na terceira pessoa"; teorias
fenomenológicas, versus objetivistas, ou "cognitivas" versus
"comportamentais" e, talvez mais comumente, análises "êmicas" versus
análises "éticas"... (1997, p. 87)

O mito construído no início da institucionalização do ofício etnográfico, que estava influenciado pelo espírito colonialista onde sujeitos pesquisavam objetos, foi se transformando junto com a incursão da antropologia noutros campos diferentes dos grupos aborígenes localizados em lugares distantes da Europa e Estados Unidos, não só porque se começa a fazer uso da antropologia para estudar as sociedades urbanas do ocidente, mas também porque nos lugares periféricos começa a se institucionalizar a formação de antropólogos/as que passarão a fazer campo em seus próprios países. Em décadas mais recentes surgiriam tendências que colocariam o pesquisador como objeto mesmo, denominado autoetnografia.

Este processo suscita uma mudança na relação dos/as etnógrafos/as com objetos vistos agora como sujeitos. Tal relação é tomada como uma negociação construtiva entre sujeitos conscientes e politicamente significantes; a etnografia, então, se produz entre a 
polifonia e a intersubjetividade dos sujeitos participantes da cena social (CLIFFORD, 1991). Neste mesmo sentido William Foote-Whyte (2005), em trabalho hoje clássico, explica que é um erro situar a pesquisa etnográfica a um nível puramente lógicointelectual, negando que o pesquisador também seja um animal social e o fato de passar longos períodos no campo faz com que seja inevitável que sua vida pessoal se veja envolvida com a pesquisa. Nesta linha se situa o enfoque metodológico que desejei incorporar na pesquisa, que como veremos mais à frente está relacionado com os diferentes trânsitos atravessados durante minha formação acadêmica.

\section{Aproximação do campo: posicionamento reflexivo como um enfoque metodológico}

A construção de um objeto de investigação por parte de uma pesquisadora não é um fato espontâneo.Este é um processo longo que obedece a diferentes escolhas e que está influenciado por aspectos sociais e contextuais da própria antropóloga. Com a intenção de situar o leitor e oferecer uma melhor compreensão, desejaria fazer um percurso sobre a maneira pela qual me aproximei e construí o campo da ajuda mútua e especificamente o grupo MADA como meu objeto.

No meu caso, a construção do objeto e, sobretudo, a aproximação do grupo esteve influenciada por aspectos metodológicos aprendidos durante minha formação como antropóloga. Desde os primeiros períodos da graduação comecei a trabalhar como estagiária no grupo de pesquisa Subjetividades contemporáneasen América Latina ${ }^{3}$. Neste coletivo, além de gerar um interesse pelo universo das subjetividades, também tive um treinamento metodológico, pois o grupo tinha uma forma particular de fazer etnografia, na qual incorporava o conceito da reflexividade, participação observante, e autoetnografia.

3 Grupo de pesquisa da Universidad Nacional de Colombia, coordenado por Carlos PinzónCastaño y Gloria Garay 
Os projetos nos quais participei tinham como objeto de estudo os jovens estudantes da Universidad Nacional de Colombia e como propósito recrutar estagiários dos cursos de antropologia e sociologia, para que se inserissem em grupos artísticos, esportivos, acadêmicos, religiosos e políticos, com a finalidade de atuar como pesquisadores situados, o que implica a criação de um si sobre o mim pesquisador, onde se explicitavam as emoções e categorias com as quais a sociedade se encarna no pesquisador. Em resumo, tentou-se fazer prática a denominada antropologia inversa, termo de Marc Augé, que consistia em aplicar nos pesquisadores os mesmos instrumentos que se aplicariam nos sujeitos da investigação. Desta forma, a reflexividade se configurou como principal ferramenta de pesquisa. Este conceito é entendido a partir de Rosana Guber como a consciência do pesquisador sobre sua pessoa e os condicionamentos sociais e políticos, as determinações inerentes à postura intelectual mesma, de modo que os fatos sociais surgem da relação e conversação entre o pesquisador e os sujeitos de estudo. Poder-se-ia então afirmar que há três tipos de reflexividade: a reflexividade enquanto membros de uma sociedade ou cultura; a reflexividade do investigador levando em conta suas perspectivas teóricas, seus interlocutores acadêmicos, seus habitus disciplinares e seu epistemocentrismo e, por último, a conversação entre a reflexividade do sujeito investigador e a do sujeito investigado, de modo que o resultado do conhecimento é a teoria emergente e co-construída" (GUBER, 2001, p. 48 - 50; PINZÓN; GARAY, 2003, p. 267)”.

Rosana Guber baseia sua argumentação da reflexividade no enfoque etnometodológico, no qual afirma que as descrições sobre a realidade não só informam sobre ela, como também a constituem. Na medida em que os sujeitos falam e atuam, vão produzindo e definindo seu mundo e a racionalidade do que fazem. Os pesquisadores sociais usam os mesmos métodos que os atores para conhecer, descrever e atuar no seu campo, só se diferenciando porque o pesquisador tem controle da reflexividade e a articulação da teoria com o campo. De igual forma, a presença do pesquisador vai constituir as situações de interação da mesma maneira que a linguagem constrói a realidade; o pesquisador então se converte no principal instrumento de pesquisa e de 
produção de conhecimento, de maneira que os dados de campo não se revelam ao etnógrafo, mas sim no etnógrafo. (GUBER, 2001, p. 45-47)

Nesta ordem de ideias, tive que me inserir num grupo e escolhi então um grupo musical denominado tuna. Estes coletivos, que existem em Portugal, Espanha e América Hispânica, são de origem espanhola e cantam músicas como pasodobles e boleros, participam também em serenatas e festivais. São vistos pela maioria das pessoas, em especial os jovens, como bizarros, ridículos e fora de moda. Tive que entrar no grupo e fazer parte dele, descobrindo que o que parecia um simples coletivo artístico na realidade era quase um grupo marcial feminino, onde não era importante só o aspecto musical (de fato este às vezes parecia o menos significante). As integrantes deveriam atravessar diferentes etapas, constituídas por uma série de duras provas físicas e morais para atingir o último estágio, que suporia uma transformação de si. E assim, além de suportar as gozações de meus colegas de faculdade, tive que enfrentar duras sessões de exercícios físicos e humilhações morais, pois se supunha que o principal valor a cultivar era a humildade. Ao mesmo tempo, no grupo de pesquisa deveria aplicar as ferramentas metodológicas, fazendo reflexões de minha vida pessoal, sendo entrevistada pelos professores e coordenadoras, exercícios que tiveram um impacto emocional bastante significativo.

O período no grupo musical passou e comecei a fazer minha monografia de graduação. Decidi incorporar elementos da reflexividade no meu estudo sobre a subjetividade, o que foi muito importante para levar a cabo a pesquisa, devido ao fato de que eu comecei a estudar um grupo protestante que queria tornar práticas algumas concepções teológicas contemporâneas, visando construir uma igreja libertária com um lema principal: "não dogmas". Novamente entrei como uma integrante do grupo. Mas a dupla posição gerou tensões bastante complexas, pois em alguns momentos foi difícil assumir a condição de investigadora, com meu lugar como integrante predominando. Além disso, no diálogo pesquisadora-pesquisados a balança pareceu se inclinar mais para o lado destes e meu lugar como etnógrafa parecia estar desaparecendo, em parte porque eu era a mais jovem do grupo, com menos preparação acadêmica e nível econômico mais 
baixo, frente a sujeitos que, além de possuir doutorado e serem professores universitários, tinham um amplo domínio da teologia. Por muito tempo durante a escritura da monografia não conseguia observar as relações de poder/saber apresentadas no grupo. Além de colocar à prova as três reflexividades propostas por Rosana Guber (sócioculturais, epistemocentrismo, diálogos entre pesquisadores e pesquisados), explorei uma última reflexividade que consiste em fazer uma contínua observação da forma sobre a qual estamos refletindo. Desta forma, dediquei um capítulo a refletir sobre minha formação acadêmica, espiritual e a forma na qual estava incorporando a reflexividade produzida a partir do diálogo com sujeitos investigados, para assim conseguir escrever os demais capítulos, buscando obter um equilíbrio entre as vozes deles e a minha. (PARDO, 2009)

\section{Construindo o objeto da dissertação}

Antes de escolher o grupo com que faria minha pesquisa de graduação, a Comunidad Menonita del Norte, transitei por vários grupos protestantes neopentecostais. Nesse lugar observei que um aspecto característico do discurso era a superação pessoal e o êxito, semelhante ao discurso da autoajuda. Assim, comecei a interessar-me por este campo, vendo nele um espaço frutífero para observar os processos de construção de sujeito, percebendo também que as ideias deste tipo de literatura estavam presentes nos discursos de uma boa parte de meu círculo de amigos, parentes, colegas de trabalho e de faculdade, onde expressões como "atitude positiva" e "êxito" eram muito comuns, sendo inclusive objetivos a se atingir. Porém, muitas destas pessoas nunca tinham lido livros de autoajuda, nem visitado grupos de ajuda mútua, ou seja, sem estar muito mergulhados no tema conseguiam expressar os principais argumentos.

Comecei a ler estudos realizados sobre o tema e percebi que a maioria analisava a literatura, mas minha intenção era ver como os discursos da autoajuda eram internalizados na construção da subjetividade, fazendo uma revisão dos possíveis espaços onde se poderia fazer a observação no Brasil. Assim, encontrei nos grupos de ajuda 
mútua um lugar adequado para fazer o estudo, especialmente no MADA, pois eu conhecia o livro "Mulheres que Amam Demais", muito popular no meu país. Minha primeira aproximação com o grupo foi feita de Bogotá, através do site: enviei uma mensagem, manifestando meu interesse e comecei a ler os textos lá colocados.

Um dia após minha chegada ao Rio de Janeiro fui conhecer um dos grupos localizados nesta cidade. Devido aos meus escassos conhecimentos de português, a visita não foi muito produtiva, pois não entendi muito. Decidi esperar um pouco, me familiarizar com a língua, para então voltar à reunião, e assim, em setembro de 2010 decidi tentar novamente uma aproximação, já com um pouco mais de fluência no idioma. Falei com a coordenadora da reunião, me apresentei como estudante do mestrado em Ciências Sociais da UERJ interessada em fazer uma pesquisa sobre o grupo. Ela me explicou que na reunião só poderiam participar membros que se identificassem com a doença de amar demais, que havia algumas reuniões abertas às mulheres alheias à irmandade ou que só estavam interessadas em conhecer, mas que esta reunião era fechada. Perguntou-me se eu também queria fazer parte do grupo e, desta forma participar de todas as reuniões e também fazer minha pesquisa sobre minha experiência no grupo. Respondi que sim e após a chegada de mais integrantes do grupo a coordenadora colocou em votação se eu poderia permanecer na sala como pesquisadora. As demais participantes me perguntaram sobre o que exatamente eu queria pesquisar e respondi que sobre o amor e os relacionamentos sexo-afetivos. Elas votaram a favor da minha permanência na sala.

Nesse momento eu aceitei entrar no grupo nessa condição, porque isto que a coordenadora me propôs, muito provavelmente sem o saber, era basicamente o enfoque da reflexividade; a partir de minha experiência poderia fazer a pesquisa. Depois de muito tempo percebi vários aspectos que diziam respeito a essa escolha, como que o fato de não me deixarem entrar sem admitir minha autodenominação como MADA já era um dado da própria pesquisa, pois mostrava a importância da identificação para o grupo. Por outro lado, tive a oportunidade de ver em duas ocasiões pessoas que se apresentaram como pesquisadoras sociais de diferentes universidades públicas, que levavam inclusive uma 
carta de apresentação assinada por ditas instituições; a elas foi negado o acesso ao grupo, sob o argumento de que só poderiam permanecer na sala as mulheres que se identificassem. Elas foram encaminhadas para falar comigo, pois eu estava "escrevendo um livro sobre o MADA", mas nenhuma delas me procurou.

\section{Entre emoção e cognição}

Desejo deixar por um momento o relato sobre meu posicionamento no campo para explicar um aspecto que me ajudou na coleta das informações e na interpretação dos dados coletados. A partir da linha da antropologia das emoções Catherine Lutz (1990) tem estudado a forma como a sociedade ocidental concebe a experiência emocional, analisando assim uma série de oposições situadas em dois eixos principais: emoção/pensamento e emoção/distanciamento.No primeiro, que é o que mais nos interessa para esta argumentação, há vários rótulos apresentados como pares de oposições: afeto/cognição, paixão/razão, sentimento/pensamento. estas oposições

possuem uma forte marca de gênero, onde os rótulos relacionados com a emoção sempre estão associados ao feminino em oposição aos da razão, associados com o masculino. (COELHO, 2010; LUTZ,1988).

Embora estas oposições sejam reforçadas na psicologia e na filosofia e estejam presentes o tempo todo no senso comum, trabalhos feitos na antropologia das emoções e na antropologia cognitiva mostram que na cena pública existe uma articulação entre cognição/emoção, presente, por exemplo, nos movimentos sociais, em especial no concernente à motivação e agência individual, ou seja, cognição se articula com a emoção no indivíduo para a ação. (COELHO, 2010) .

A partir da Antropologia cognitiva, autoras como Claudia Strauss e Naomi Quinn (1994), influenciadas pela teoria da prática de Bourdieu, têm construído um modelo conexionista propondo um arquétipo da mente que articula a emoção, motivação e as forças sociais que modelam e são modelados pelas pessoas, que se baseia em representações internalizadas que não são regras rígidas; pelo contrário, são uma rede 
flexível de associações, onde os pensamentos e ações não se tomam da realidade diretamente, mas sim por protótipos aprendidos que permanecem na memória onde as sensações como as visões, os sons, os cheiros fazem parte da forma como entendemos. As autoras usam a analogia com as unidades neuronais nas quais existem redes especializadas, e também há outras redes que se ativam e se desativam de acordo com a combinação de estímulos e determinadas mensagens.Da mesma forma, nos esquemas culturais não existe um ensino intencional, dado que o aprendizado é flexível de acordo com a situação, e surge no transcorrer da cotidianidade. Não se deve confundir com os esquemas computacionais baseados em poucas regras, mas sim em esquemas que podem se transformar dependendo de reações subjetivas, que poderiam até torná-los improvisados e espontâneos. (JIMENO, 2004)

Minha proposta então é aplicar estas argumentações teóricas ao ofício etnográfico. De fato, metodologicamente as emoções sempre foram presentes no trabalho de campo, como afirma Roberto DaMatta (1981, p.30) parafraseando Levi-Strauss "os sentimentos e as emoções são os hóspedes não convidados da situação etnográfica". Nesta pesquisa poderíamos afirmar que foram os convidados de honra na forma como se interpretou e se recolheu os dados, pois considero que resulta contraditório pensar um modelo teórico que observa as emoções fazendo parte da forma como os indivíduos entendem o mundo, e ao mesmo tempo pensar que os etnógrafos e etnógrafas poderíamos fazer uma abstração racional do mundo social que não estivesse "poluído" por uma carga afetiva. O que nos faria diferentes dos outros indivíduos?

Em resumo, minha proposta não pretende ser inovadora.Desejo somente ressaltar um aspecto que sempre esteve presente nas análises etnográficas, me diferenciando então só por fazê-lo explícito. Claro que isto não é novo: outros autores já refletiram sobre o assunto, como Helio Silva que afirma que a escrita, a observação etnográfica e a experiência teórica são absorvidas emocionalmente (1993, p.153) e sensorialmente a partir dos cinco sentidos, que de fato modelam a situação etnográfica (2009, p.186). Por sua parte, Gilberto Velho (1981), contestando a proposta de Da Matta 
de transformar "o exótico em familiar e o familiar em exótico", argumenta que este último processo torna-se possível:

quando somos capazes de confrontar intelectualmente e mesmo emocionalmente, diferentes versões e interpretações existentes a respeito de fatos, situações. O estudo de conflitos, disputas, acusações, momentos de descontinuidade em geral é particularmente útil, pois, ao se focalizarem situações de drama social, pode-se registrar os contornos de diferentes grupos, ideologias, interesses, subculturas etc., permitindo remapeamento da sociedade. $\mathrm{O}$ estudo do rompimento e rejeição do cotidiano por parte de grupos ou indivíduos desviantes ajuda-nos a iluminar, como casos limites, a rotina e os mecanismos de conservação e dominação existentes(1981,p.45)

Continuando com meu relato sobre as questões metodológicas desenvolvidas durante o trabalho decampo,meu papel no grupo foi bastante ativo, fiz parte da junta administrativa, desempenhando o cargo de secretaria, de tesoureira e de representante de intergrupo. Dada minhas experiências anteriores no enfoque da reflexividade considero que desta vez aproveitei mais sem diluir-me no grupo. Consegui, por exemplo, experimentar em minha própria pele o fato de falar de minha vida privada para pessoas que não conhecia e poder ter momentos de desabafo que interpretei como rituais catárticos, momentos que no começo achei muito incômodos, mas que com o tempo e quase sem perceber, comecei inclusive a desfrutar. Também comecei a utilizar em minha vida pessoal o conhecimento sobre como gerenciar as relações sociais professado no grupo, aplicado por meio de microtecnologias, que são denominadas assertividade e limites. Numa conversa informal entre as participantes do grupo sobre as doenças físicas e sua associação com as doenças emocionais, falou-se que os problemas relacionados com os rins eram o resultado da falta de afetividade.Lembrei-me que tinha tido uma série de moléstias nesse aspecto e me perguntei: será que eu tenho esse problema? Logo refleti sobre o interessante que poderia ser esse dado para minha análise. Com esta série de episódios comecei a perceber que os dados recolhidos no campo se revelavam em mim.

A identificação com o grupo não só serviu para fazer aproximação inicial ao campo; também foi importante ao longo de todo o processo porque o fato de sentir em minha própria pele repercutiu literalmente em meu corpo. Comecei a observar que aspectos nos quais nunca antes prestei atenção como a arrumação de meu cabelo, unhas e 
maquiagem começavam agora a tomar importância em meu cotidiano e sobretudo no dia da reunião, aspectos que muito sutilmente eram cobrados pelas participantes do grupo, pois em algumas ocasiões me eram recomendados certos penteados, tom de tintura do cabelo, salões de beleza, tipos de brincos entre outras coisas.

Nesta mesma linha, posso afirmar que sem perceber comecei a ter um envolvimento emocional com as participantes do grupo, talvez porque passasse muito tempo com elas, e comecei a fazer diferentes planos, inclusive participar de reuniões festivas como aniversários, shows, chás entre outros. Posso afirmar que muitas delas se converteram em minhas amigas, que me brindaram com muito carinho e acolhimento, questões que para uma pessoa recém-chegada a um país tem muito valor. Durante a reunião muitas vezes comecei a me sentir bastante comovida por alguns dos dramas expressados, sobretudo no inicio, sentimentos que algumas vezes se transformaram em decepção quando a pessoa parecia ter saído do drama e voltava a recair. Embora sempre tentasse escutar mais do que falar, tal como mandam os manuais de etnografia, principalmente nas conversas depois da reunião, em muitas ocasiões não consegui ficar em silêncio. Houve um dia em que senti que tinha errado como etnógrafa, quando fiz um comentário muito forte que quase acaba em briga com uma participante: durante várias ocasiões esta pessoa tinha afirmado só gostar de homens que tinham dinheiro. Como ela tinha sido maltratada por este tipo de homem, em um momento me exaltei e tentei convencê-la de que estava errada e que deveria observar outros aspectos nos homens, como o respeito. Durante vários dias me senti culpada por ter cometido esta imprudência e o fantasma do pesquisador objetivo parecia me atormentar; depois comecei a compreender que todos esses sentimentos, indignação, dor, aborrecimento, sofrimento pela pena alheia, faziam parte da forma como os dados se me estavam revelando.

Em especial lembro-me da história de uma mulher que me comoveu demais. Conheci em profundidade sua historia a partir de uma entrevista que me fez sentir muita pena. Fiquei pensando nos problemas desta pessoa durante vários dias, porque o que mais me impactava no seu relato, além dos sofrimentos que tinha experimentado com vários homens, era que ela parecia fazer exatamente tudo o que os livros do grupo indicavam. 
Participava há mais de sete anos do grupo, mas sua vida sentimental não parecia melhorar, encontrando-se numa imensa solidão. Em várias oportunidades recebi telefonemas seus, nos quais falava de suas dificuldades e no começo pensei em encontrar estratégias como apresentar-lhe um amigo, embora nunca o tenha feito. Estes pensamentos eram constantes quando escutava um relato comovente; percebi que talvez a única maneira que eu tinha para ajudá-las era ceder um pouco de meu tempo para escutar seus problemas, tal como elas faziam comigo. Com o passar dos dias esta pessoa conheceu um homem que parecia muito bom, que tinha tudo o que ela tinha me manifestado querer, e até se comprometeram em casamento, o que me produziu uma felicidade enorme. A partir deste fato comecei a observar que eu tinha passado muito tempo no grupo e que, além desta história tinha visto como se desenvolviam as histórias de outras mulheres. Observei pessoas que chegavam ao grupo e a forma como mudavam suas vidas depois de alguns meses, também outras que deixavam de participar; novas salas que eram abertas e transformações no esquema das reuniões, ou seja, poderia afirmar, seguindo William FooteWhyte (2005, p.320), que eu fazia uma filmagem diacrônica das vidas dos sujeitos e não uma fotografia sincrônica.

O fato de fazer uma observação participante tão ativa também trouxe problemas. Em várias oportunidades me vi envolvida em conflitos relacionados com fofocas que na maioria das vezes estavam associadas à forma de administração do grupo, visto que a estrutura dos grupos de ajuda mútua tem uma orientação democrática na qual se deve tomar decisões a partir de votações. Em algumas oportunidades há pessoas que tomam decisões individuais, o que gera bastante inconformidade nas participantes, sobretudo nas mais antigas. Na medida em que eu desempenhava alguns encargos, embora tentasse evitar o conflito nem sempre isso foi possível; contudo, observei que tais situações faziam parte da mesma convivência social.

\section{O trabalho que elas faziam sobre mim}

Varias situações me mostravam a imagem que as participantes do grupo tinham construído em torno de mim, como as já relatadas sobre as pesquisadoras que tentaram 
entrar no grupo e não conseguiram, e que foram encaminhadas para falar comigo, sob o argumento de que eu já estava "escrevendo um livro sobre o grupo". Por outro lado, numa oportunidade uma delas comentou-me que sabia que no começo eu entrara no grupo com o interesse de fazer a pesquisa, mas que ela sabia que depois eu tinha percebido que também era doente. Esta imagem às vezes parecia contrária para outras pessoas que achavam que eu tentei disfarçar meus problemas afirmando que queria fazer uma pesquisa, que isso fazia parte de meu processo denominado como a fase da negação; fui inclusive advertida por elas que talvez meu grande problema era ter um alto nível de estudo, o que me impedia de ver uma realidade mais simples e aprender sobre a experiência mais "mundana". Muitas vezes me interrogaram sobre o que tratava minha pesquisa, sobretudo no começo, em particular pelas mulheres que de alguma maneira estavam envolvidas no âmbito acadêmico, em especial as psicólogas e as assistentes sociais. Sempre respondi e expliquei qual parte de meu trabalho estava adiantando de forma sucinta, porque parecia que minhas argumentações, por exemplo, sobre a história do amor, não eram muito interessantes para elas e por momentos achava que o que na realidade queriam era uma resposta sobre como arrumar seus problemas, algo do qual eu não tinha a mínima noção.

Outra das imagens que consegui observar foi quando uma pessoa me disse que eu era um bom testemunho de recuperação, devido ao fato de que minha história não era do tipo "fundo de poço", pois a imagem deixada pela telenovela Mulheres Apaixonadas ${ }^{4}$ era que o grupo servia para pessoas muito adoecidas, que tinham enfrentado situações-limite, e que talvez uma história mais simples como a minha poderia fazer com que mais pessoas se identificassem e participassem da irmandade; acrescentou ainda que, aliás, eu tinha conseguido fazer grandes avanços em pouco tempo, sempre me orientando para desempenhar o encargo de coordenadora, o que nunca aceitei, porque este lugar além de geralmente trazer muitos conflitos, além disso, não era um lugar conveniente para fazer a observação dado sua centralidade no funcionamento do grupo o que talvez não permitiria ter uma concentração adequada nos depoimentos e nas diferentes situações

4 Telenovela emitida na emissora Rede Globo de televisão, em Outubro de 2010, Autor Manoel Carlos . 
que aconteciam na sala; um lugar mais periférico possibilitava uma observação mais panorâmica dos fatos.

\section{O contágio}

Outra perspectiva sobre a qual desejaria refletir é a da imagem externa que se tem sobre o grupo, que tem atingido de alguma maneira a legitimação da minha pesquisa e que poderia resumir como um sentimento quase geral de não compaixão e banalização. Cada vez que comentava sobre o meu tema, tanto em âmbito acadêmicos quanto fora deles, observava caras de assombro e/ou risos incontidos e depois vinham as perguntas como: Isso existe? Não posso acreditar! Essas mulheres não têm muito que fazer! Depois, geralmente lembravam-se da telenovela Mulheres Apaixonadas, onde uma das protagonistas participou do grupo MADA. Desta forma, comecei a entender que o sofrimento experimentado pelas participantes do MADA, além de não produzir compaixão, produzia graça.

Mas o sofrimento experimentado pelas participantes do MADA é muito doloroso para elas e sempre muito cômico para os demais, principal razão para a existência do anonimato do grupo. Tentei achar explicações para o porquê da banalização deste sofrimento. A primeira hipótese que tentei problematizar está relacionada com a hierarquização do sofrimento, que ficou claro quando conversava com alguns colegas que riam do sofrimento no MADA sobre o porquê do seu riso. A maioria das explicações estava relacionada ao fato de eles morarem em países como Brasil ou Colômbia, com tantos problemas de violência e de desigualdades sociais, o que dificultava que se compadecessem e entendessem porque um grupo de mulheres se reúne para sofrer por amor.

Por outra parte, o fato de se compadecer poderia produzir certa identificação com este sofrimento, e consequentemente, um "contágio", ou seja, o compassivo pode se ver como uma MADA não declarada; talvez seja por isso que as mais indignadas com a existência de MADA sempre eram as mulheres e os que mais ridicularizavam a situação 
eram os homens. O contágio também tem me atingido como pesquisadora, pois sempre se pergunta se sou uma MADA, recaindo também sobre a pesquisa, que por sua vez tem sofrido numa certa banalização.

Outro aspecto referente à não produção de compaixão pelo sofrimento das MADA's está relacionado à estética. Embora desde o início do chamado "boom do counselling" e dos discursos de autoajuda os relacionamentos tenham sido alvo dos aconselhamentos, estes foram destinados para a esfera privada; ou seja, as pessoas compravam um livro ou assistiam a um vídeo, podendo fazer uso das mesmas estratégias das MADA's, porém na esfera privada, fazendo um cultivo solitário de si. A surpresa que gera este grupo de ajuda é que deslocou da prática privada para um âmbito público, sendo visto então como quase uma paródia do que seria um grupo de alcoólicos anônimos.

Existe outro fato que poderia explicar a falta de compaixão que produz o grupo. Poderia estar relacionado com o modelo teórico exposto por Candace Clark (1990)sobre o tema da gramática da compaixão nos Estados Unidos. Através da dicotomia responsabilidade/azar a autora explica que para gerar pena frente a um determinado infortúnio a pessoa deve se apresentar como a vítima quem não teve controle sobre a situação, pelo contrário, se o infortúnio foi dado pela má intenção, malevolência, negligência ou pelo risco corrido, ou seja, ser representado como o responsável da situação, a compaixão diminui. Desta forma, poderíamos entender que o MADA não produz compaixão no exterior do grupo porque suas integrantes se apresentam como as responsáveis pelo seu sofrimento. Esta hipótese foi confirmada quando observei que algumas das poucas pessoas que sentiam pena pelo sofrimento das participantes do MADA achavam que elas eram vitimas de violência doméstica.

\section{Evitando a dissolução}

É ainda necessário esclarecer que o fato de ter colocado em relevância que as emoções foram protagonistas no trabalho de campo, associado à aplicação do enfoque da 
reflexividade, exigiu a elaboração de uma segunda parte deste relato metodológico, pois como afirma Clifford Geertz (1997), se deve encontrar um equilíbrio entre a experiência próxima e distante. Como diz Geertz,como fazer uma etnografia sobre bruxaria sem ser escrita por uma bruxa nem ficar sistematicamente surda às tonalidades de sua existência, ou seja, uma etnografia sobre bruxaria escrita por um geômetra. Como expliquei no começo do texto, na primeira experiência etnográfica, devido à minha falta de experiência por momentos fiquei diluída no grupo. Nesta oportunidade também precisei fazer exercícios de distanciamento para exteriorizar o fenômeno, e evitar novamente ficar diluída, pois é diferente estudar um grupo como A.A. ou Narcóticos Anônimos, onde o vício é uma substância determinada;há pessoas que freqüentam, em condição de membros, especificamente estas irmandades e nunca consumiram tóxicos e não têm problemas com a bebida ${ }^{5}$. No MADA é mais fácil se identificar do que se exteriorizar, visto que "o problema" são os relacionamentos, os quais são assuntos mais cotidianos, ou seja, quem não teve problemas de ordem sentimental ou conflitos com outras pessoas? De fato muitas delas afirmam que a maioria das mulheres são MADAs e que qualquer pessoa pode facilmente se identificar com algumas de suas características. De fato uma hipótese inicial é que é o discurso prescritivo da ajuda mútua e da autoajuda constrói o sujeito doente e por sua vez o transforma em doente em recuperação. Assim, comecei a observar quais poderiam ser os aspectos que me diferenciavam do grupo. O primeiro, o fato de ser estrangeira, o que por muito tempo parecia não ter muita relevância. Ninguém me perguntava de onde era ou como era minha cidade. Isto era estranho para mim, pois na maioria dos lugares que frequentei isso é sempre um tema recorrente na conversação. No MADA, as perguntas sempre eram sobre meus problemas de ordem sentimental. Mas para mim, ser estrangeira era uma grande diferença, dado que em minha cidade as habitantes têm fama de ser distantes, ensimesmadas, e, sobretudo, reservadas. Comecei a ver que não só no MADA, mas também em vários lugares do Rio de Janeiro (como filas de banco, salas de espera de consultório médico, ônibus), as pessoas conversavam sobre

5 Durante o campo observe que varias mulheres participaram de grupos como A.A e N.A sem ter problemas com o álcool nem com drogas, este foi um fato que não consegui abordar a profundidade, contudo observei que as razoes pela que isto acontece, desde minha interpretação, é que o grupo de ajuda brinda um espaço de socialização, desta maneira estas mulheres encontravam lá um espaço para interagir com outras pessoas especialmente com homens. 
sua vida privada com muita facilidade. Numa oportunidade, por exemplo, me sentei a conversar com os trabalhadores de uma oficina mecânica, que fica no prédio onde moro, com os quais nunca antes havia falado. Em dado momento me senti como se estivesse numa sala do MADA, versão masculina, pois estas pessoas começaram a contar aspectos sentimentais, que pra mim eram muito íntimos e, constantemente, reclamavam da dificuldade de ter relacionamento sexo-afetivo.

As perguntas que me faziam as participantes do grupo eram sobre minha pesquisa e, sobretudo, meus problemas de ordem sentimental. Este último aspecto usei como outra estratégia reflexiva, dado que já tive decepções amorosas. Durante o campo contraí matrimônio, mantendo um relacionamento estável e bem sucedido. Isto vai se tornar uma diferença muito importante, dado que a maioria das pessoas do grupo não tem um relacionamento ou está em processo de separação. Contudo a estratégia mais frutífera tenha sido a identificação de categorias emic e etic, principalmente nos tipos ideais. Por exemplo, no grupo constantemente se fala de padrões de MADA os quais figuram a nível prescritivo na literatura, como controle e obsessão. Estes se diferenciam daqueles criados a partir da participação observante, através das experiências relatadas pelas participantes, que considero serem papéis momentâneos, tal como a namorada que está tentando acabar o relacionamento, a esposa que está em processo de divórcio, solteiras que tentam encontrar uma pessoa, as amantes que tentam acabar com essa posição, seja para acabar o relacionamento ou para se posicionar como esposa.

Para terminar, a última estratégia reflexiva usada para o distanciamento é a inversão de um aspecto muito recorrente nos discursos e na literatura: considerar que se descobriram como MADA ("eu não sabia que era MADA"). Penso que ao invés de se descobrir o que existe é um processo de construção, ou seja, existe um marco prescritivo que cria a categoria MADA, perspectiva a partir da qual estas mulheres recriam suas experiências amorosas. 


\section{Alguns aspectos sobre a análise das gramáticas emocionais}

Como apontamos nas primeiras linhas deste capitulo, a reflexão seria feita em torno dos problemas da ordem metodológica, contudo achamos importante mostrar alguns dos aportes que deixaram a pesquisa em sua totalidade, que teve como objetivo a analise das gramaticas emocionais no grupo MADA .

O primeiro aporte diz respeito à construção histórica do amor no Ocidente, aspecto visto através do rastreio de algumas pistas que mostraram a circulação de ideias em torno do amor, o que facilitou o seu encaixe no formato dos doze passos, podendo assim ser catalogado como vício e/ou doença. Pois no grupo MADA o amor é visto como um vício ou uma doença, que seria crônica, sem cura e, não tratada, poderia levar à morte. Esta caracterização se deve, em parte, à estrutura própria dos grupos de ajuda mútua que nasceram a partir da adaptação dos princípios dos Alcoólicos Anônimos, grupo que deslocou o alcoolismo da esfera moral para a saúde. A adaptação do formato dos doze passos e as doze tradições a outro tipo de situações contribui para criar um processo de patologização de outras questões, tais como a adição às drogas, ao cigarro, ao jogo e, inclusive, assuntos antes cotidianos que agora são vistos como nocivos: comida, dívidas e emoções em excesso, entre outros.

Contudo, existem aspectos associados à construção histórica e social do amor que nos mostram que o amor visto como doença não é tão recente; ao contrário, há ideias antigas a respeito que fizeram com que o amor, assim como o sexo, pudesse ser encaixado no formato dos grupos de ajuda mútua. Por esta razão pretendeu-se mostrar como se tem vivenciado o amor nas diferentes épocas, tendo como fio condutor o rastreio do amor de uma perspectiva negativa, porque como se mostrou na analise teórica, este foi mais desqualificado e estigmatizado do que louvado, na maioria das vezes por seu excesso, ou seja, parece que o amor não tem sido o problema, somente sua quantificação desmedida.

A segunda questão se encontra relacionado com o amor que chamamos de contemporâneo, este teve como característica central a ambivalência, pois se apresentou 
de forma oscilante. Por um lado, o amor é o tema central da felicidade veiculado na cultura de massa; por outro lado, graças à medicalização do cotidiano, situa-se no extremo oposto, sendo patologizado por seu excesso como no caso do MADA, aspecto este que ficou plasmado na imagem do doce sonho e o eterno pesadelo. Poderíamos afirmar então que a ambivalência é a forma contemporânea de vivenciar a experiência amorosa.

O terceiro aspecto que desejaríamos pontuar, relacionado à patologização do amor, é a participação dos grupos de ajuda mútua, e por extensão da autoajuda, na psicologização do cotidiano. Esta pesquisa sobre o MADA e especificamente sobre a literatura do grupo mostrou que existe um discurso que constrói categorias tais como "família disfuncional", "autoconhecimento", "diálogo" e "autoestima" que atuam como prescrição de maneiras de atuar e de agir, nas quais os sujeitos recriam suas experiências. Estas categorias prescrevem maneiras "corretas" de amar e tudo o que não coincida com aqueles parâmetros é visto como "doentio".

$\mathrm{Na}$ análise das gramáticas emocionais, observamos também, que o "amar demais" pode ser considerado como doentio devido ao fato de que o excesso quebraria com o ideal estético do amor, o que, por sua vez, também está relacionado com a ruptura da dádiva, ou seja, elas amam demais e não são correspondidas na mesma medida. Como forma de solução deste impasse o grupo propõe então uma série de práticas que interpretamos como uma "economia dos vínculos sociais", nas quais há uma racionalização do sentimento amoroso na medida em que se pensa quanto se deve "investir" num relacionamento, o que na maioria das vezes está determinado pelo tempo e pelo dinheiro. Tempo e dinheiro são vistos aqui como categorias moralizantes que permitem fazer juízos de valor sobre situações e pessoas, o que se poderia resumir no seguinte questionamento: quem merece ou não o meu tempo e o meu dinheiro?

Essa racionalização perpassa o amor e os relacionamentos sexual-afetivos e é utilizada na experiência de outras emoções, inclusive as interações vivenciadas no interior do grupo. Vemos assim que a dádiva parece ser a linguagem que configura a maneira como se sente o amor e outras emoções. Neste sentido, por exemplo, observamos 
que a compaixão também aparece como um investimento a longo prazo para a pessoa compassiva, que espera receber uma retribuição quando necessário.

Para finalizar, desejaríamos apontar que esta análise do grupo MADA contribuiu para observar duas questões que falam de aspectos sociais a nível macro: em primeiro lugar, a crítica ao amor excessivo que prega o MADA é contrária aos ideais como os da cultura de massa, que colocam a paixão desbordante como o objeto de prazer e tema central da felicidade, mostrando assim a variabilidade histórica e cultural da experiência amorosa. Esta ideia espera ser uma contribuição ao campo de estudo da antropologia das emoções. A segunda questão mostrada por esta pesquisa foi que no processo de patologização da vida, no qual a psicologização tem uma participação ativa, vemos que a autoajuda e ajuda mútua parecem surgir como "antídotos" que resolveriam quase todas as situações que no mundo moderno são vistas como "males". Neste sentido, o trabalho pretende dialogar com a linha da antropologia da saúde e a doença.

\section{Referencias Bibliográficas:}

CLARK, Candece. Misery and company: sympathy everyday life. London: University of Chicago Press, 1992.

CLIFFORD, James. 1991, Sobre la autoridad etnográfica, In: C. Geertz, J. CLIFFORD, El surgimiento de la antropología posmoderna.México: Editorial Gedisa, p. 141170 .

COELHO, Maria Claudia. As emoções e a ordem pública: uma investigação sobre modelos teóricos para a análise sócio-antropológica das emoções. REUNIÃO BRASILEIRA DE ANTROPOLOGIA, Belém, Pará, agosto 2010.

DAMATTA, Roberto, o oficio do etnólogo, ou como ter anthropological blues. In:NUNES, Edson De oliveira (org). A aventura sociológica. Rio de Janeiro: Zahar, 1981

GEERTZ, Clifford. Do ponto de vista dos nativos: a natureza do entendimento antropológico. In: O saber local, Petrópolis: Vozes, 1997.

GUBER, Rosana. La etnografía. Método, campo y reflexividad. Bogotá: Norma, 2001. 
Hélio, Silva, Travesti. A Invenção do Feminino. Rio de Janeiro: Relume-Dumará, ISER, 1993.

JIMENO, Myriam. Crimen pasional: contribución a una antropología de las emociones. Bogotá: Universidad Nacional de Colombia, 2004.

LEVI-STRAUSS, Claude. As estruturas elementares do parentesco. Pretrópolis: Vozes, 2009.

LEVI-STRAUSS, Claude. Introdución a La obra de Marcel Mauss. In: Sociologia y antropologia de Marcel Mauss. Madrid: editorial Tecnos, 1979.

LUTZ, Catherine. Engendered emotion: gender, Power and the rhetoric of emotional controlin American Discourse. In: LUTZ, Catherine Lutz ; ABU-LUGHOD, Lila(orgs.) Language and the politics of emotion.Cambridge: Cambridge University Press, 1990.

PARDO, Astrid Johana. Transgrediendo dogmas: un estudio etnográfico de la contro ${ }^{0}$ cción de subjetividades en la comunidad menonita del norte. Trabajo de grado para optar al título de antropóloga, Departamento De Antropología Facultad De Ciencias Humanas Universidad Nacional De Colombia. Bogotá: 2009.

PINZÓN, Carlos Ernesto y Gloria Garay A. Diálogos con la vida diálogos con la teoría: ejercicios de reflexividad en antropología, 2003. No prelo.

REZENDE, Claudia. COELHO, Maria Claudia. Antropologia das emoções. Rio de janeiro: FGV, 2010.

STRAUSS, Claudia; QUINN, Naomi .A cognitive/cultural anthropology. In: BOROFSKY, Robert(ed.). Assessing cultural anthropology. Nueva York, St. Louis: McGraw Hill, 1994.

VELHO, Gilberto. Indivisualismo e cultura. "observando o familiar. In: NUNES, Edson de Oliveira (org.).A aventura sociológica. Rio de Janeiro Zahar 1981

WHYTE, William Foote. Sociedade de esquina. Rio de Janeiro: Zahar Editor. 2005. 